\title{
PENENTUAN LOKASI EXTERNAL WAREHOUSE DENGAN MENGGUNAKAN METODE CENTER OF GRAVITY (STUDI KASUS DI PT. RPZ SURABAYA)
}

\section{DETERMINATION OF EXTERNAL WAREHOUSE LOCATION USING THE CENTER OF GRAVITY METHOD (CASE STUDY AT PT. RPZ SURABAYA)}

Rahman Soesilo1), Yahdi Firmansyah'2), Sartono ${ }^{3)}$

1,2,3) Sekolah Tinggi Teknologi Mutu Muhammadiyah, Tigaraksa, Tangerang, 15710, Indonesia

\section{ARTICLE INFORMATION \\ Article history: \\ Received: April 08, 2020 \\ Revised: April 16, 2020}

Accepted: Mei 27, 2020

Keywords:

Location

External Warehouse

Center of Gravity

Supply Chain

\section{A B S T R A C T}

Determination of the External Warehouse location has a vital role in the Supply Chain Management system to facilitate the delivery process to consumers who can run smoothly, quickly, and the most optimum distance. The company needs to build a new external warehouse because the current warehouse will be used for new machine installations. Therefore, it was decided to create an alternative external warehouse outside the factory. The purpose of this study is to determine the optimum location of the external warehouse to be made. This study uses the Center of Gravity method to calculate the optimal area that will be considered by the location between the distribution of consumer locations and the number of shipments and also consider the size of the factory that will supply the product. Based on the results of this study, calculations using the Center of Gravity method found that the location of the external warehouse chosen was at $(-7.328293,112.7420916)$, the settlement area of Jemur Wonosari, Wonocolo, Surabaya City, East Java. By determining the exact location of the external warehouse, the company will benefit from the efficiency of transportation costs.

\section{A B S T R A K}

Penentuan lokasi gudang eksternal memiliki peran penting dalam sistem Manajemen Rantai Pasokan untuk memfasilitasi proses pengiriman kepada konsumen sehingga proses produk dapat terkirim dengan lancar, cepat dan jarak yang paling optimal. Perusahaan saat ini membutuhkan gudang eksternal karena area gudang yang ada akan digunakan untuk instalasi mesin baru. Oleh karena itu, diputuskan untuk membuat alternatif gudang eksternal di luar pabrik. Tujuan dari penelitian ini adalah untuk menentukan lokasi gudang eksternal yang paling optimal untuk dibuat. Penelitian ini menggunakan metode Center of Gravity untuk menghitung lokasi optimal yang sesuai dengan lokasi antara lokasi konsumen dan jumlah pengiriman dan juga mempertimbangkan lokasi pabrik yang akan memasok produk. Dari hasil penelitian ini, perhitungan menggunakan metode Center of Gravity menemukan bahwa lokasi gudang eksternal yang dipilih berada di $(-7.328293,112.7420916)$, yaitu daerah Jemur Wonosari, Wonocolo, Kota Surabaya, Jawa Timur. Dengan menentukan lokasi yang tepat dari gudang eksternal, perusahaan akan mendapat manfaat dari efisiensi biaya transportasi.
${ }^{*}$ Corresponding Author

Name : Rahman Soesilo

E-mail: Rahmansusilo537@gmail.com
This is an open access article under the CC-BY license.

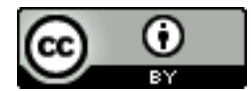




\section{PENDAHULUAN}

Di dunia global ini, perusahaan bersaing satu sama lain untuk menjadi yang terbaik. Perusahaan yang bisa memuaskan konsumennya dengan penyerahan produk yang lebih cepat dan berkualitas dibandingkan pesaingnya akan bisa bertahan dan yang tidak mampu mengimbangi maka akan tersisih. Perusahaan yang terlibat dalam industri kemasan plastik mempunyai tantangan lain yaitu permintaan harga dari konsumen dan perubahan desain [1].

PT. RPZ Surabaya didirikan lebih dari 25 tahun yang lalu merupakan produsen kemasan plastik. Dalam hal ini, perusahaan PT. RPZ Surabaya berfokus untuk memproduksi botol dan tutup dengan material seperti PP, HDPE dan PET. Proses produksi didalam pembuatan tutup dan botol yang dilakukan dalam perusahaan ini adalah: Blow Moulding untuk botol HDPE serta PP, Injection Moulding untuk tutup botol dan ISBM untuk botol PET. Dalam aplikasinya di konsumen untuk botol dan tutup ini banyak diperuntukkan segmen kosmetik, obat dan juga pelumas. Beberapa tahun terakhir, permintaan konsumen terus meningkat cukup tinggi, sehingga kapasitas produksi yang ada tidak dapat memenuhi kebutuhan konsumen. Oleh karena itu, perusahaan mempunyai rencana untuk menambah jumlah mesin produksinya. Akan tetapi, rencana penambahan mesin produksi ini mempunyai keterbatasan yaitu area pabrik yang sudah tidak bisa bertambah lagi, sehingga ada rencana untuk sebagian area warehouse dijadikan area produksi. Dengan bertambahnya kapasitas produksi serta berkurangnya area warehouse maka diperlukan external warehouse untuk melakukan penyimpanan sementara hasil produksi sebelum dikirim ke konsumen.

Dalam rencana penentuan lokasi external warehouse ini, maka diperlukan beberapa kajian yang cukup detail agar dapat mencapai lokasi yang cukup efisien dan strategis. Hal ini berkaitan dengan pengaturan dari bergeraknya perpindahan produk dari suatu titik asal hingga berakhir pada lokasi konsumen untuk memenuhi permintaan yang dibutuhkan. Kompleksitas dalam suatu aliran logistik dapat dianalisa serta diuraikan menjadi suatu sebuah model, serta dijadikan visualisasi dan optimalisasi dengan simulasi yang ada [2]. Dalam rangka untuk menurunkan biaya transportasi, meningkatkan efisiensi distribusi dan meningkatkan kinerja logistik maka pemilihan lokasi yang tepat untuk external warehouse menjadi hal yang sangat penting [3]. Penentuan lokasi external warehouse ini harus mempertimbangkan jarak serta frekuensi pengiriman ke konsumen yang paling optimum dan juga mempertimbangkan pengiriman produk dari pabrik. Dalam melakukan penentuan lokasi external warehouse ini, peneliti menggunakan metode Center Of Gravity (COG), yang merupakan salah satu metode untuk menentukan suatu lokasi dengan tepat dengan berdasarkan beberapa variabel yaitu jarak pengiriman barang serta frekuensi dari pengiriman barang ke konsumen tersebut. Keunggulan dari Center Of Gravity (COG) adalah lebih mudah untuk menentukan lokasi dikarenakan perhitungan berdasarkan letak longitude dan attitude sehingga mempunyai akurasi dan presisi yang lebih baik [4].

Berbagai penelitian telah melaporkan bahwa pengunaan metode Center of Gravity dapat memberikan informasi penentuan lokasi gudang baru yang lebih optimal yang dapat meminimalkan biaya. Penelitian sebelumnya, Anshori [5] di dalam penelitian ini dilakukan pemilihan lokasi terbaik diantara beberapa alternatif lokasi fasilitas cross dock untuk menyokong kebutuhan logistik retail modern di Surabaya. Dengan menggunakan metode Center of Gravity (COG) didapatkan Lokasi fasilitas cross dock yang paling kecil costnya adalah lokasi alternatif dengan TC: sebesar 43.359,2 yang berada di daerah Surabaya Timur. Effendi [6] penelitian ini menentukan lokasi pengumpul limbah B3 skala provinsi di Jawa Timur menggunakan metode Center of Gravity berdasarkan pada biaya transportasi yang minimal. Selain itu perancangan gudang dan identifikasi risiko tempat pengumpulan limbah B3 skala provinsi juga dilakukan. Dalam penelitian ini menggunakan data koordinat penghasil limbah B3, volume limbah B3 serta biaya transportasi didapatkan dari hasil diskusi dengan salah satu transporter limbah B3 di Jawa Timur. Hasil perhitungan didapatkan titik koordinat lokasi pengumpulan limbah B3 skala provinsi di Jawa Timur. Rully [7] melakukan penelitian pada PT. Elang perdana Tyre Industry dimana penelitian ini bertujuan untuk menganalisis biaya dengan lokasi gudang di Bogor yang mengakibatkan biaya transportasi yang ditanggung oleh perusahaan cukup besar, hal ini dikarenakan jarak yang jauh antara gudang dengan para distributornya. Metode penelitian yaitu metode center of gravity (COG) yang akan digunakan untuk melakukan analisa. Dari hasil perhitungan dengan menggunakan metode center of gravity maka dapat di tentukan lokasi gudang baru dengan titik koordinat $X=122, Y=22$, yang berlokasi di Solo. Dengan lokasi gudang baru yang berlokasi di Solo tersebut maka akan dapat 
meminimalkan jarak tempuh dan biaya transportasi dari gudang di Bogor. [8] Dalam penelitian ini bertujuan untuk membahas penggunaan metode Center of Gravity (COG) dan Factor Rating pada pemindahan lokasi kantor dan pabrik PT. Sublimindo dikarenakan Lokasi PT. Sublimindo kurang strategis. Metode COG ini menentukan lokasi titik tengah koordinat dari berdasarkan lokasi suppliernya dan Metode Factor Rating untuk menentukan gedung-gedung yang berpotensi dan membandingkan jumlah nilai bobot dari setiap gedung tersebut untuk menentukan gedung yang memiliki nilai paling tinggi sebagai lokasi alternatif untuk PT. Sublimindo berdasarkan titik koordinat yang dihasilkan oleh metode COG. Hasilnya, Setelah dilakukan analisis menggunakan Metode COG dan Factor Rating untuk menentukan lokasi alternatif yang dulu lokasi antara PT. Sublimindo dan Supllier berjarak 12-14km sekarang hanya 1$2 \mathrm{~km}$ dan yang biasa menghabiskan biaya sebesar Rp. 72.000 .000 untuk biaya pemesanan sementara jika di hitung dari titik lokasi alternatif hanya menghabiskan biaya Rp. 28.800.000

Dengan konsep penelitian yang hampir sama dengan sebelumnya, maka penelitian ini akan lebih memperkuat penelitian yang sudah berhasil dalam menentukan pemilihan lokasi dengan menggunakan metode Center of Gravity (COG). Penelitian ini bertujuan untuk mendapatkan lokasi external warehouse yang paling optimum agar biaya transportasi dapat ditekan seminimal mungkin tanpa mengurangi waktu pengiriman [9]

\section{METODE PENELITIAN}

Data ini diperoleh dari hasil pengukuran langsung plotting maps aplikasi Google Maps. Data-data yang diambil adalah titik kordinat masing-masing lokasi konsumen. Metode penelitian dilakukan melalui pengamatan dan pengambilan data langsung dilokasi penelitian di PT RPZ Surabaya. Penelitian ditentukan berdasarkan landasan teori yang ditulis mengenai kajian penerapan metode penentuan lokasi external warehouse dengan metode Center of Gravity. Selain data diatas , data juga dari data sekunder ini meliputi:

1. Laporan barang masuk.

2. Laporan barang keluar.

3. List dan alamat konsumen PT. RPZ Surabaya

Data ini diperoleh dari laporan harian PT RPZ Surabaya. Laporan barang masuk dan keluar, serta total volume yang didistribusikan ke masingmasing konsumen yang dikonversi dalam bentuk ritasi dari truk, sesuai data yang diambil dari desember 2019 sampai dengan februari 2020. Objek penelitian ini berada lokasi pabrik PT RPZ Surabaya. Objek tersebut berkaitan dengan nama-nama, alamat konsumen dari PT RPZ Surabaya, titik kordinat dari masing-masing konsumen, dan banyaknya barang yang didistribusikan untuk masing-masing konsumen PT RPZ Surabaya.

Metode Center of Gravity adalah teknik penentuan lokasi yang akan digunakan merupakan teknik kuantitatif dan matematis untuk menemukan lokasi external warehouse yang akan meminimalkan biaya pengiriman [10]. Metode Center of Gravity mengasumsikan bahwa biaya secara langsung bersifat proporsional dengan jarak dan banyaknya barang yang diangkut. Lokasi yang ideal adalah lokasi yang membuat jarak tertimbang antara gudang dan outlet pengecernya menjadi minimal, jarak ini diberi bobot sesuai dengan banyaknya kontainer yang diangkut [2]. Terdapat beberapa data yang perlu disiapkan sebelum mengolahnya dengan metode Center of Gravity, antara lain titik koordinat dari setiap lokasi konsumen PT RPZ Surabaya yang dimiliki karena dalam penelitian ini proses pencarian external warehouse akan menyesuaikan dengan letak atau lokasi konsumen yang dimiliki oleh perusahaan. Untuk mengetahui titik koordinat, akan menggunakan aplikasi Google Maps. Pengumpulan data lainnya, yaitu berupa data kuantitas barang yang dikirim dari gudang atau diterima oleh konsumen merupakan data sekunder yang dapat didapatkan melalui data internal perusahaan.

Rumus yang digunakan untuk menghitung dengan metode pusat gravitasi dapat dilihat sebagai berikut [11]:

$$
\begin{gathered}
C x=\frac{\sum_{i} d_{i x} w_{i}}{\sum_{i} w_{i}} \\
C y=\frac{\sum_{i} d_{i y} w_{i}}{\sum_{i} w_{i}}
\end{gathered}
$$

$$
\begin{aligned}
& \text { Dimana: } \\
& \text { Cx=koordinat } x \text { dari lokasi awal } \\
& \text { Cy=koordinat } y \text { dari lokasi awal } \\
& \text { Dix= koordinat } x \text { dari lokasi i } \\
& \text { Diy= koordinat } y \text { dari lokasi } i
\end{aligned}
$$


$\mathrm{Wi}=$ volume barang yang dipindahkan atau dari lokasi

Langkah - langkah perhitungan metode Center of Gravity (COG) untuk menentukan lokasi external warehouse yang paling optimal [9] adalah sebagai berikut :

a. Menentukan titik koordinat masingmasing konsumen.

b. Menentukan total volume atau berat pengiriman ke masing-masing konsumen.

c. (Koordinat $\mathrm{X}$ konsumen) $\mathrm{x}$ (Total demand konsumen) dijumlahkan sesuai jumlah konsumen dan dibagi Total demand konsumen.

d. (Koordinat $Y$ konsumen) $x$ (Total demand konsumen) dijumlahkan sesuai dengan jumlah konsumen dan dibagi Total demand konsumen.

e. Koordinat konsumen didapat berdasarkan hasil dari $\mathrm{X}$ dan $\mathrm{Y}$.

Pengolahan Data yang telah tersedia selanjutnya di tentukan sesuai dengan variable yang dibutuhkan dalam penelitian ini, yang meliputi total ritasi truk atau frekuensi masing masing konsumen, area distribusi konsumen, titik koordinat. Data-data yang telah berhasil dikumpulkan selanjutnya akan diolah dengan mengunakan metode Center of Gravity, metode ini digunakan untuk mengetahui lokasi external warehouse baru yang bisa disarankan untuk lokasi penyimpanan produk PT RPZ Surabaya. Data-data yang dibutuhkan adalah titik kordinat masing-masing konsumen dan total volume yang didistribusikan ke area tersebut.

\section{HASIL DAN PEMBAHASAN}

Data yang dikumpulkan adalah data terkait dengan konsumen PT RPZ Surabaya nama konsumen, alamat dan area distribusi, titik koordinat dan volume dari masing-masing barang yang didistribusikan ke masing-masing konsumen PT RPZ Surabaya. Nama-nama dan alamat konsumen dari PT RPZ Surabaya ini merupakan data awal untuk dapat menentukan lokasi, titik koordinat konsumen PT RPZ Surabaya.

Data barang terkirim adalah pengeluaran barang yang dikirimkan beserta total bok yang didistribusikan ke masing-masing konsumen. Dari data ini yang selanjutnya akan digunakan untuk memetakan area pengiriman PT RPZ Surabaya dan menentukan rekomendasi di lokasi mana external warehouse yang paling optimal.
Pengeluaran barang PT RPZ Surabaya pada bulan Desember 2019 sampai dengan Februari 2020, disajikan dengan menampilkan total truk atau ritasi yang didistribusikan ke konsumen PT RPZ Surabaya. Grafik dari pengiriman ke konsumen 3 bulan terakhir dalam perhitungan ritasi atau truk adalah sebagai berikut :

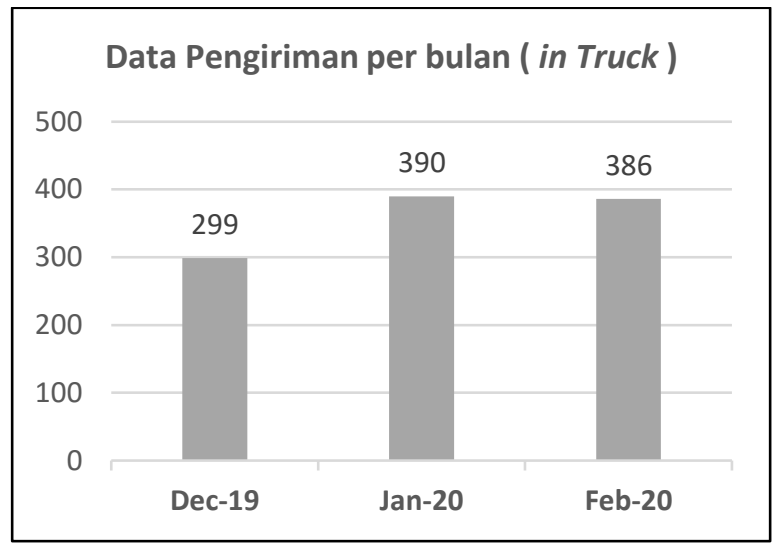

Gambar 1 . Data pengiriman per bulan

Dari gambar 1 grafik data pengiriman per bulan PT. RPZ Surabaya, selama 3 bulan tersebut, rata - rata pengiriman ke konsumen adalah 358 truk dengan tren yang cenderung stabil setiap bulannya. Selanjutnya pengolahan data dilakukan dengan menghitung jumlah truk total selama 3 bulan tersebut yang dikirimkan ke masing-masing konsumen dengan juga menentukan titik koordinat dari masing-masing lokasi konsumen tersebut.

Penentuan titik koordinat dibutuhkan sebagai variabel penelitian, untuk bisa menentukan titik koordinat masing - masing konsumen. Data konsumen yang digunakan adalah semua konsumen yang memiliki atau terkait dengan pendistribusian selama kurun waktu 3 bulan tersebut yaitu mulai Desember 2019 hingga Pebruari 2020. Nama - nama konsumen yang terkait proses pengiriman selama periode tersebut dapat diketahui, berdasarkan alamat konsumen tersebut kemudian diambil dan ditentukan titik koordinat dengan mengunakan alat bantu aplikasi google maps. Data pencarian google maps sebagai mana gambar 2 Pengambilan koordinat konsumen PT RPZ Surabaya. 


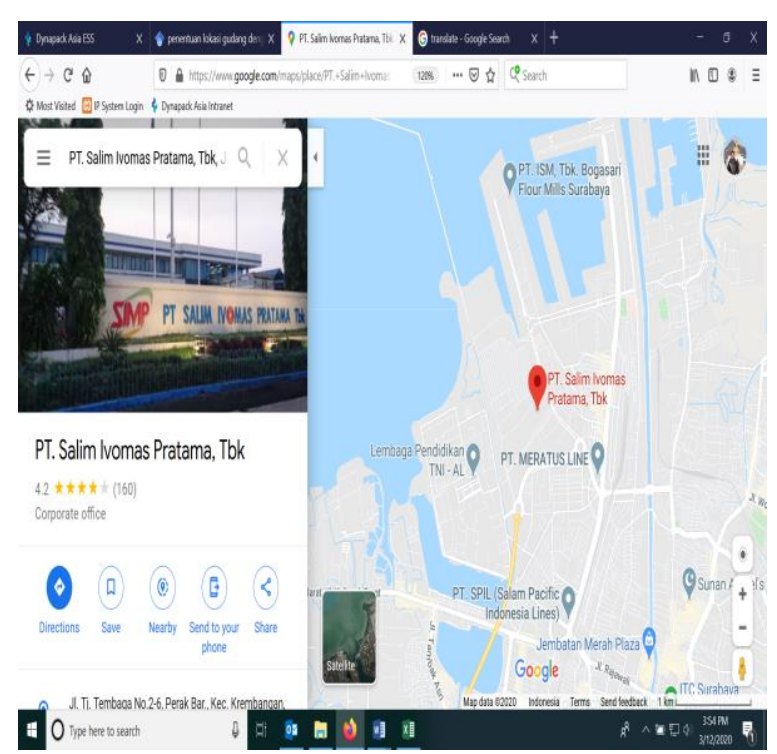

Gambar 2. Pengambilan koordinat konsumen PT RPZ Surabaya.

Selanjutnya, setiap masing masing konsumen akan diambil titik koordinatnya dengan tetap menggunakan aplikasi google maps. Dari hasil pemetaan koordinat tersebut, maka dibuat dalam sebuah tabel dimana koordinat akan dibuatkan dalam kolom X dan Y. Bukan hanya titik koordinat dari masing - masing konsumen ini saja yang akan dijadikan acuan untuk menentukan lokasi external warehouse, akan tetapi lokasi koordinat PT RPZ Surabaya ini juga dijadikan penentu. Hal ini disebabkan, setiap produk yang akan dikirim ke konsumen di supply atau diproduksi di pabrik ini. Ini yang sering disebut dengan data inbound yaitu jumlah produk yang harus dikirimkan gudang sebagai hasil produksi dari pabrik ini yang akan disimpan dan dipersiapkan untuk pengiriman ke konsumen. Jumlah penerimaan ini akan lebih banyak dibandingkan dengan jumlah terkirim, hal ini disebabkan produksi akan membuat stok sejumlah barang untuk disimpan di external warehouse ini.

Berdasarkan data konsumen serta lokasi pabrik sebelumnya, maka dibuat dalam sebuah tabel. Tabel 1 ini dibawah adalah titik titik koordinat dari konsumen serta koordinat dari lokasi PT.RPZ Surabaya tersebut. Pengambilan koordinat ini disesuaikan dengan alamat masing masing serta diambil data koordinat dari google maps.

Tabel 1. Titik koordinat konsumen dan PT RPZ Surabaya

\begin{tabular}{llrc}
\hline Customer & \multicolumn{1}{c}{ Lokasi } & $\mathbf{X}$ & Y \\
\hline PT.RPZ & Rungkut & -7.344 & 112.7568 \\
BDF & Singosari & -7.870 & 112.6793 \\
\hline
\end{tabular}

\begin{tabular}{|c|c|c|c|}
\hline Customer & Lokasi & $\mathbf{X}$ & $\mathbf{Y}$ \\
\hline Coronet & Taman & -7.351 & 112.7044 \\
\hline LNK & Kutorejo & -7.554 & 112.5363 \\
\hline Malidas & Buduran & - 7.426 & 112.7296 \\
\hline Mitrapak & $\begin{array}{l}\text { Rungkut } \\
\text { tengah }\end{array}$ & -7.333 & 112.7577 \\
\hline Novaph & $\begin{array}{l}\text { Kepati } \\
\text { han }\end{array}$ & -7.241 & 112.5919 \\
\hline PIM & Tegalsari & -7.280 & 112.7330 \\
\hline $\begin{array}{l}\text { Salim } \\
\text { ivomas }\end{array}$ & Kremba & -7.217 & 112.7222 \\
\hline Usfi & Kedin & -7.226 & 112.7722 \\
\hline Vitaphrm & $\begin{array}{l}\text { Panjang } \\
\text { Jiwo }\end{array}$ & -7.307 & 112.7623 \\
\hline $\begin{array}{l}\text { Henson } \\
\text { Farma }\end{array}$ & $\begin{array}{l}\text { Karang } \\
\text { pilang }\end{array}$ & -7.345 & 112.6836 \\
\hline
\end{tabular}

Pada penelitian ini, teknik penentuan lokasi external warehouse yang akan digunakan adalah metode Center of Gravity yang merupakan teknik kuantitatif dan matematis untuk menemukan lokasi external warehouse yang akan meminimalkan biaya pengiriman. Dalam menemukan lokasi terbaik untuk menjadi external warehouse diperhitungkan lokasi konsumen, volume barang yang dikirim ke konsumen, dan biaya pengangkutan [12]. Metode Center of Gravity yang digunakan dalam penentuan lokasi external warehouse yang tepat adalah total ritasi atau truk dan titik koordinat masing-masing konsumen dari PT RPZ Surabaya dalam 3 bulan terakhir tersebut seperti pada tabel 2.

Tabel 2. Ritasi per bulan dari konsumen

\begin{tabular}{lcccc}
\hline Customer & $\begin{array}{c}\text { Dec } \\
\mathbf{2 0 1 9}\end{array}$ & $\begin{array}{c}\text { Jan } \\
\mathbf{2 0 2 0}\end{array}$ & $\begin{array}{c}\text { Feb } \\
\mathbf{2 0 2 0}\end{array}$ & Total \\
\hline PT.RPZ & 264 & 359 & 359 & 982 \\
BDF & 4 & 2 & 2 & 8 \\
Coronet & 2 & 35 & 39 & 76 \\
LNK & 2 & & 3 & 5 \\
Malidas & 95 & 88 & 92 & 275 \\
Mitrapak & 5 & 5 & 4 & 14 \\
Novaphrin & 9 & 10 & 9 & 28 \\
PIM & 6 & 13 & 13 & 32 \\
Salim & 104 & 153 & 134 & 391 \\
ivomas & & & & \\
Usfi & 6 & 10 & 11 & 27 \\
Vitapharm & 31 & 40 & 50 & 121
\end{tabular}




\begin{tabular}{lcccc}
\hline Customer & $\begin{array}{c}\text { Dec } \\
\mathbf{2 0 1 9}\end{array}$ & $\begin{array}{c}\text { Jan } \\
\mathbf{2 0 2 0}\end{array}$ & $\begin{array}{c}\text { Feb } \\
\mathbf{2 0 2 0}\end{array}$ & Total \\
\hline $\begin{array}{l}\text { Henson } \\
\text { Farma }\end{array}$ & & 3 & 2 & 5 \\
\hline & 528 & 718 & 718 & $\mathbf{1 9 6 4}$ \\
\hline
\end{tabular}

Dan jika dibuat dalam sebuah Pie Diagram, maka ada 2 konsumen yang paling mayoritas dalam pengiriman yang dilakukan oleh PT. RPZ Surabaya. Hal ini dapat dilihat secara langsung dalam grafik gambar 3 sebagai berikut :

\section{Data Pengiriman}

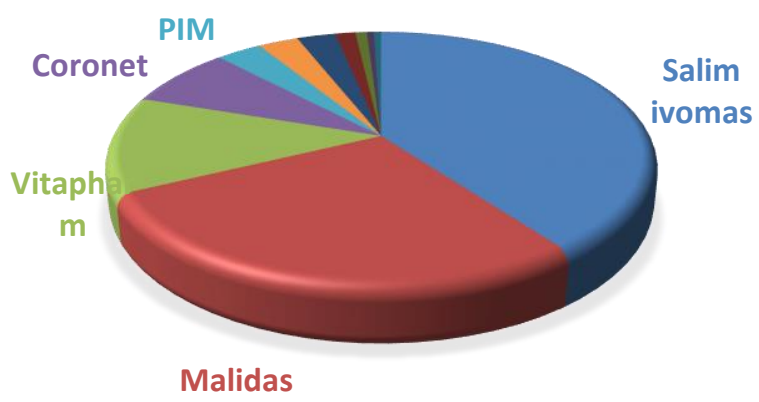

Gambar 3. Data pengiriman konsumen

Pengolahan data dengan rumus Center of Gravity dijabarkan sebagai berikut : Cx merupakan hasil koordinat $x$ dari perhitungan pusat gravitasi, Cy merupakan koordinat y dari pusat gravitasi, dix merupakan koordinat $x$ dari setiap lokasi pelanggan PT RPZ Surabaya diy merupakan koordinat y dari lokasi konsumen PT RPZ Surabaya, dan Wi adalah volume barang yang dipindahkan atau dari lokasi external warehouse. Setelah diketahui titik koordinat atau lokasi terbaik dan ideal berdasar metode Center of Gravity, kemudian ini akan disampaikan sebagai usulan kepada perusahaan. Tentunya ini memerlukan analisis lebih lanjut secara deskriptif mengenai lokasi tersebut dan pengaruhnya terhadap perusahaan.

Berdasarkan rumus Center of Gravity diatas, maka dilakukan perhitungan setiap titik koordinat dengan dikalikan jumlah ritasi atau truk masing masing masing titik. Berdasarkan perhitungan tersebut, nantinya akan didapat jumlah total dari seluruh koordinat $\mathrm{x}$ dan $\mathrm{y}$ yang akan dimasukkan kedalam rumusan Center of Gravity untuk menentukan titik koordinat yang paling optimal untuk external warehouse yang akan dipakai tersebut. Tabel dari perhitungan ritasi atau truk dengan titik titik koordinat $X$ masing masing pengiriman, dapat dibuat dalam tabel 3 sebagai berikut ini :

Tabel 3. Perhitungan Center of Gravity pengiriman koordinat $X$

\begin{tabular}{llcc}
\hline Customer & \multicolumn{1}{c}{$\mathbf{X}$} & Total & $\mathbf{X i}$ \\
\hline PT.RPZ & -7.344 & 982 & -7212.02 \\
BDF & -7.87083 & 8 & -62.9666 \\
Coronet & -7.35173 & 76 & -558.732 \\
LNK & -7.55441 & 5 & -37.7720 \\
Malidas & -7.42632 & 275 & -2042.23 \\
Mitrapak & -7.33341 & 14 & -102.667 \\
Novphrin & -7.24142 & 28 & -202.759 \\
PIM & -7.28087 & 32 & -232.980 \\
Salim & -7.21713 & 391 & -2821.89 \\
ivomas & & & \\
Usfi & -7.22663 & 27 & -195.119 \\
Vita & -7.30777 & 121 & -884.240 \\
pharm & & & \\
Henson & -7.34549 & 5 & -36.7274 \\
Farma & & & \\
\hline & & $\mathbf{1 9 6 4}$ & $\mathbf{- 1 4 3 9 0 . 1}$
\end{tabular}

Selanjutnya dibuat tabel perhitungan ritasi atau truk dengan titik titik koordinat $Y$ masing masing pengiriman, dapat dibuat dalam tabel 4 sebagai berikut ini :

Tabel 4. Perhitungan Center of Gravity pengiriman koordinat $Y$

\begin{tabular}{lccc}
\hline Customer & $\mathbf{Y}$ & Total & $\mathbf{Y i}$ \\
\hline PT.RPZ & 112.756 & 982 & 110727.18 \\
BDF & 112.6793 & 8 & 901.43440 \\
Coronet & 112.7044 & 76 & 8565.5344 \\
LNK & 112.5363 & 5 & 562.68179 \\
Malidas & 112.7296 & 275 & 31000.649 \\
Mitrapak & 112.7577 & 14 & 1578.6085 \\
Novapharin & 112.5919 & 28 & 3152.5755 \\
PIM & 112.7330 & 32 & 3607.4562 \\
Salim & 112.7222 & 391 & 44074.400 \\
ivomas & & & \\
Usfi & 112.7722 & 27 & 3044.8496 \\
\hline
\end{tabular}




\begin{tabular}{lccl}
\hline Customer & $\mathbf{Y}$ & Total & \multicolumn{1}{c}{ Yi } \\
\hline Vita pharm & 112.7623 & 121 & 13644.244 \\
$\begin{array}{l}\text { Henson } \\
\text { Farma }\end{array}$ & 112.6836 & 5 & 563.41836 \\
\hline & & & \\
\hline & & $\mathbf{1 9 6 4}$ & $\begin{array}{l}\mathbf{2 2 1 4 2 3 . 0 3} \\
\mathbf{9 7 7 9}\end{array}$ \\
\hline
\end{tabular}

Sehingga akan diperoleh koordinat pengiriman untuk Xi dan Yi seperti terdapat pada tabel 5 sebagai berikut :

Tabel 5. Hasil Perhitungan Center of Gravity Xi dan Yi

\begin{tabular}{lllc}
\hline Cstomer & Lokasi & Xi & Yi \\
\hline PT.RPZ & Rungkut & -7212.0 & 110727.1 \\
BDF & singosari & -62.96 & 901.4344 \\
Coronet & Taman & -558.73 & 8565.534 \\
LNK & kutorejo & -37.772 & 562.6817 \\
Malidas & buduran & -2042.2 & 31000.64 \\
Mitrapak & $\begin{array}{l}\text { Rungkut } \\
\text { tengah }\end{array}$ & -102.66 & 1578.608 \\
Nova & kepatihan & -202.75 & 3152.575 \\
pharin & tegalsari & -232.98 & 3607.456 \\
PIM & Kremba & -2821.8 & 44074.40 \\
Salim & ngan & & \\
ivomas & Kedin & -195.11 & 3044.849 \\
Usfi & ding & & \\
& Panjang & -884.2 & 13644.24 \\
Vita & & \\
pharma & Jiwo & & \\
Henson & Karang & -36.72 & 563.4183 \\
Farma & pilang & & \\
\hline & & $\mathbf{- 1 4 3 9 0 .}$ & $\mathbf{2 2 1 4 2 3 .}$ \\
& & $\mathbf{1 3 9 5 1 8}$ & $\mathbf{0 3 9 7 7 9}$ \\
\hline
\end{tabular}

Dan selanjutnya menggunakan rumus dari Center of Gravity sebagai berikut [12] pada rumus 1 dan rumus 2.

Maka didapatkan titik lokasi external warehouse yang terpilih adalah pada koordinat (-7.328293, 112.7420916), Jika dilihat pada aplikasi google maps koordinat tersebut terletak didaerah kawasan Jemur Wonosari, Wonocolo, Surabaya City, East Jawa pada gambar 4.

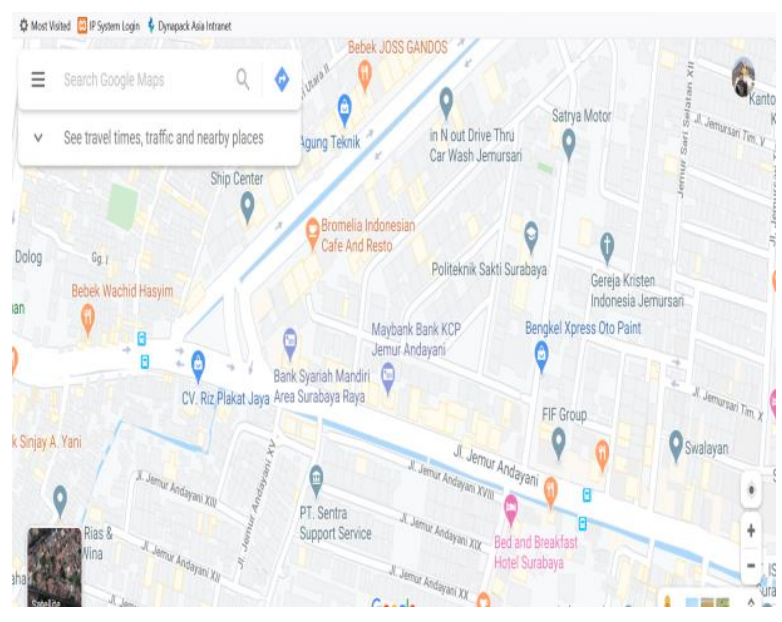

Gambar 4. lokasi external warehouse yang disarankan.

Lokasi yang berada ditengah tengah antara beberapa konsumen yang memiliki total volume pengiriman terbesar pada saat ini merupakan sebuah keuntungan yang dapat dimanfaatkan oleh PT RPZ Surabaya. Hal ini disebabkan proses distribusi merupakan kunci utama kesuksesan aktivitas logistik dan rantai pasok [13]. Setelah dilakukan perhitungan jarak kilometer antara konsumen ke lokasi gudang yang lama dengan konsumen ke gudang baru ada penurunan jumlah kilometer dalam satu bulan sebanyak $339 \mathrm{~km}$. Dengan penurunan jumlah Kilometer tersebut, maka ada pengurangan biaya transportasi dan juga ada peningkatan kecepatan pengiriman. Lokasi usulan external warehouse yang berada di tengah kota, memiliki sisi keuntungan dan kerugian tersendiri. Dengan berada di pusat kota, perusahaan dapat melayani kebutuhan setiap konsumen dengan baik karena jarak yang harus ditempuh menjadi lebih singkat [14], akan tetapi dari segi perundang-undangan dan tata ruang kota, diperlukan kajian lebih lanjut mengenai lokasi tersebut. Hal tersebut diperlukan untuk memberikan pandangan yang lebih luas kepada perusahaan untuk menghasilkan keputusan yang baik. Perusahaan juga tetap harus memperhatikan syarat-syarat lokasi external warehouse yang baik, diantaranya sebagai berikut [4] :
a. Mengklasifikasi karakteristik dari barang yang akan disimpan di gudang tersebut. Yaitu : Besar dari kemasan produk, Jumlah ritasi pengiriman serta quantity produk yang akan diterima di external warehouse, Jumlah ritasi pengiriman serta quantity .
b. Kondisi sekitar external warehouse dan juga kondisi kelaikan bangunan.
c. Mengidentifikasi produk yang disimpan di external warehouse termasuk kategori


barang berbahaya atau tidak.

Selain hal - hal tersebut, terdapat juga hal-hal penting harus diperhatikan oleh perusahaan sebelum memutuskan atau memilih lokasi dari external warehouse adalah faktor kesesuaian terhadap peraturan atau perundangan serta juga diperlukan identifikasi faktor keamanan sekitar area tersebut [15]. Karena dalam memilih dan menentukan lokasi, yang merupakan investasi jangka panjang, memerlukan pertimbangan lain seperti halnya memperhatikan jenis barang yang akan disimpan serta karakteristik dari barang tersebut, banyaknya barang yang akan disimpan untuk perhitungan luas tempat yang diperlukan dan waktu yang diperlukan untuk menyimpan barang tersebut serta kebijakan dan keinginan dari perusahaan agar lokasi yang dipilih dapat menunjang tujuan bisnis perusahaan.

Hasil penelitian pada akhirnya dapat mengetahui bagaimana besar dampak lokasi external warehouse terhadap nilai tambah suatu perusahaan yang menunjukkan bahwa lokasi yang efisien sangat berpengaruh positif. Sehingga disarankan bagi pelaku - pelaku industri agar benar-benar mempertimbangkan penentuan lokasi external warehouse perusahaan, karena sangat mempengaruhi perolehan efisiensi dari biaya transportasi yang dikeluarkan. Semakin efisien suatu industri memilih lokasi, maka akan semakin optimum biaya transportasi yang akan dikeluarkan [16].

\section{KESIMPULAN}

Metode Center of Gravity digunakan sebagai alat untuk membantu manajemen perusahaan yang akan membuat gudang diluar lokasi produksi, dalam menentukan lokasi external warehouse nya, dengan mempertimbangkan jarak antara perusahaan dengan konsumen yang paling efisien dari segi biaya dan waktu. Dimana dalam penelitian ini, terdapat pengurangan jumlah kilometer sebanyak $339 \mathrm{~km}$ dalam satu bulan.

Penentuan lokasi external warehouse untuk PT. RPZ Surabaya ini dengan menggunakan metode Center of Gravity di dapatkan titik lokasi external warehouse yang terpilih adalah pada koordinat (7.328293, 112.7420916), terletak di daerah kawasan Jemur Wonosari, Wonocolo, Surabaya City, East Java. Untuk pengembangan dari penelitian ini, maka dapat dilakukan penelitian selanjutnya yaitu dengan menentukan lokasi External warehouse untuk konsumen yang diluar propinsi Jawa timur.

\section{DAFTAR PUSTAKA}

[1] L. Lukmandono, R. Soesilo, M. Basuki, And M. J. Hidayat, "Minimasi Waktu Penggantian Cetakan Dengan Pendekatan Lean Manufacture \& Single Minute Exchange Of Dies (Smed)," 2018. http://hdl.handle.net/11617/10629

[2] S. Zice, L. Zhengping, Q. Runtao, And S. Mansoor, "Agent-Based Logistics Coordination And Collaboration," Logist. Integr. Group, Autom. Technol. Gr., 2001. https://pdfs.semanticscholar.org/a2d6/331 a00f60c2c3b5d8eb60c44a7eae452686a.p df

[3] C.-R. Wu, C.-T. Lin, And H.-C. Chen, "Optimal Selection Of Location For Taiwanese Hospitals To Ensure A Competitive Advantage By Using The Analytic Hierarchy Process And Sensitivity Analysis," Build. Environ., Vol. 42, No. 3 , Pp. 1431-1444, 2007. https://doi.org/10.1016/j.buildenv.2005.12. 016

[4] B. Irwanto, "Penentuan Lokasi Distribution Center Produk Farmasi Dengan Menggunakan Metode Center Of Gravity Dan Analytical Hierarchy Process (Studi Kasus Di Pt. Jkt)." Universitas Mercu Buana Jakarta, 2018. https://repository.mercubuana.ac.id/id/epri $n t / 45228$

[5] M. Anshori, A. F. Fudhla, And A. Hidayat, "Penentuan Lokasi Fasilitas Crossdock Pada Kota Metropolis Dengan Pendekatan Center Of Gravity," Tek. Eng. Sains J., Vol. 1, No. 2, Pp. 83-88, 2017. http://dx.doi.org/10.5281/zenodo.1116473

[6] D. O. Effendi, "Penentuan Lokasi Pengumpulan Limbah B3 Di Jawa Timur Dengan Menggunakan Metode Center Of Gravity." Institut Teknologi Sepuluh Nopember, 2017.

http://repository.its.ac.id/id/eprint/44503

[7] T. Rully And D. C. Aldenia, "Penggunaan Metode Center Of Gravity Dalam Penentuan Lokasi Gudang Terhadap Meminimkan Biaya Transportasi Pada Pt Elangperdana Tyre Industry," Jimfe (Jurnal IIm. Manaj. Fak. Ekon., Vol. 6, No. 1, Pp. 64-69, 2018. https://doi.org/10.34203/jimfe.v6i1.494 
[8] R. Riady And T. Aspiranti, "Penentuan Lokasi Alternatif Kantor Dan Pabrik Pt . Sublimindo Dengan Menggunakan Metode Center Of Gravity Dan Factor Rating," Pros. Manaj., 2019. http://hdl.handle.net/123456789/25351

[9] E. Nur Fu'ad, "Pengaruh Pemilihan Lokasi Terhadap Kesuksesan Usaha Berskala Mikro/Kecil Di Komplek Shopping Centre Jepara," Media Ekon. Dan Manaj., 2016, Doi: 10.24856/Mem.V30i1.234.

[10] N. Kudláčková And J. Chocholáč, "Warehouse Location Problem In Context Of Delivery Time Shortening," In Matec Web Of Conferences, 2017, Doi:10.1051/Matecconf/201713400029.

[11] J. Heizer And B. Render, Operations Management Sustainability And Supply Chain Management 11th Edition. 2014.

[12] J. Heizer, B. Render, And C. Munson, Operations Management. Prentice-Hall, 2008.

[13] D. B. Paillin And M. T. Dasfordate, "Metode Center Of Gravity Dan Point Rating ( Studi Kasus Di Kabupaten Seram Bagian Barat ),$"$ Arika,

2012.

https://ojs3.unpatti.ac.id/index.php/ari $\underline{\mathrm{ka} / \text { article/view/510 }}$

[14] H. A. Sudrajat, "Penentuan Lokasi Kantor Cabang Laboratorium Lingkungan Hidup Menggunakan Metode Center Of Gravity Di Provinsi Jawa Barat," Oper. Excell. J. Appl. Ind. Eng., 2019, Doi:10.22441/Oe.V.10.3.2018.018.

[15] F. B. Susetyo, "Peningkatan Kondisi Area Bahan Laboratorium Produksi Teknik Mesin Fakultas Teknik Universitas Negeri Jakarta," J. Kaji. Tek. Mesin, Vol. 1, No. 1, Pp. 1-8, 2016. http://journal.uta45jakarta.ac.id/index. $\mathrm{php} / \mathrm{jktm} / \mathrm{article} / \mathrm{view} / 327$

[16] Z. Almetova, V. Shepelev, And S. Shepelev, "Cargo Transit Terminal Locations According To The Existing Transport Network Configuration," In Procedia Engineering, 2016, Doi:10.1016/J.Proeng.2016.07.335.

\section{Biografi Penulis}

Rahman Soesilo S.Kom, MT.

Lahir di Malang pada tanggal 5 Mei 1972. Riwayat pendidikan sarjana (S1) Teknik Informatika Universitas Budiluhur Jakarta lulus tahun 2004, pendidikan magister (S2) Teknik Industri ITATS Surabaya lulus tahun 2018. Riwayat pekerjaan sebagai Plant Manager PT, Dynapack Asia 2017 - . Dosen Teknik Industri Sekolah Tinggi Mutu Muhammadiyah Tangerang 2019

\section{Yahdi Firmansyah, S.T, M.T.}

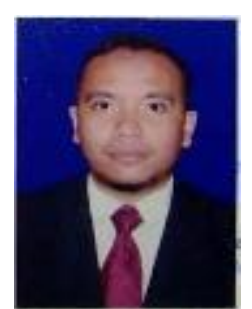
Lahir di Jakarta pada tanggal 9 Maret 1991. Riwayat pendidikan Ahli Madya (D3) Teknik Elektro Politeknik Negeri Jakarta tahun 2011, pendidikan sarjana (S1) Teknik Elektro Universitas Pancasila 2014, pendidikan magister (S2) Teknik Industri Universitas MercuBuana lulus 2018. pekerjaan Dosen Teknik Elektro di Politeknik Negeri Jakarta 2019. Dosen Teknik Industri di Sekolah Tinggi Teknologi Mutu Muhammadiyah Tangerang 2019.

\section{Sartono, M.T.}

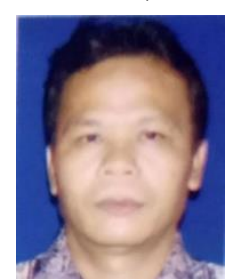

Lahir di Klaten pada tanggal 19 Juni 1970. sarjana (S1) Teknik Industri Sekolah Tinggi Teknologi Mutu Muhammadiyah lulus tahun 2015, pendidikan magister (S2) Teknik Industri Universitas MercuBuana lulus 2019. pekerjaan Staf Bagian Administrasi Urusan Keuangan di Sekolah Tinggi Teknologi Mutu Muhammdiyah 2002. Dosen Teknik Industri di Sekolah Tinggi Teknologi Mutu Muhammadiyah Tangerang 2017. 